\title{
Polymer Functionalization as a Powerful Tool to Improve Scaffold Performances
}

\author{
Filippo Rossi, $\mathrm{PhD}, 1$ and Martijn van Griensven, $\mathrm{MD}, \mathrm{PhD}^{2}$
}

To address the increasing need for improved tissue substitutes, tissue engineering seeks to create synthetic, three-dimensional scaffolds made from polymeric materials, incorporating cells and growth factors to induce new tissue formation. Materials science, in conjunction with biotechnology, can satisfy these needs by developing artificial, synthetic substitutes and organ implants. Here, scaffold ability to promote cell growth and differentiation is a key point and, in this framework, orthogonal chemistry has led the field of biomaterial science into a new area of selective, versatile and biocompatible nature. In particular, the possibility to modify and functionalize scaffolds with compounds that are able to improve mechanical properties or cell viability and improve their differentiation in a tailorable manner opens new opportunities for researchers. In this review, we seek to emphasize the recent endeavors of exploiting this versatile chemistry toward the development of new cell culture scaffolds.

\section{Introduction}

$\mathbf{T}$ ISSUE OR ORGAN transplantation is severely limited by the problems of donor shortage and immune rejection by receiving patients. Developments and recent achievements in tissue engineering allow the transplantation of cells from a patient's own tissue to regenerate damaged tissues or organs, avoiding adverse immune responses. ${ }^{1,2}$ Several recent developments point toward the combined use of cells together with specific drugs to enhance regenerative therapeutic effects. ${ }^{3,4}$ In this framework, three-dimensional (3D) biomaterial-made scaffolds were first developed as a temporary substrate to grow cells in an organized fashion, before performing the transplantation of such combined structures. ${ }^{5}$ Direct injection of in vitro-cultured cells is one attractive alternative. ${ }^{6}$ However, concerns emerge while trials are performed: the injected cells very often leave the zone of injection, as they are not confined by any support; thereby, they easily get into the circulation migrating all over the body toward a rather uncertain fate. Hence, joining materials science together with biotechnology and engineering is considered to be a promising strategy for developing 3D scaffolds that could help tissue replacement. ${ }^{7,8}$ In particular, recent advances in materials science have provided an abundance of innovations, underlining the leading role of polymers in this field. ${ }^{9,10}$ To design substitutes with improved biocompatibility, tissue engineers seek to create synthetic, three dimensional (3D) scaffolds made from polymeric materials incorporating cells or growth factors to induce the growth of novel tissue. ${ }^{11,12}$ As a result, strong attention is paid to synthetic and natural polymers as they can be used to fabricate 3D scaffolds and also to develop injectable systems for tissue engineering. ${ }^{3}$ On one hand, synthetic polymers can be tuned in terms of composition, rate of degradation, mechanical and chemical properties. On the other hand, naturally derived polymers provide structures extremely similar to living tissues such as stimulating a specific cellular response, which sometimes supersedes the advantages of synthetic polymers. ${ }^{12}$ Moreover, owing to their similarity with the extracellular matrix (ECM), natural polymers present higher biocompatibility in vitro and in vivo, but the possibility to induce immune reactions in humans is their main drawback.

Despite some good results in the last years, the attention of research is moving to orthogonal selective chemistry applied to polymer functionalization as a powerful tool able to increase scaffold performances. ${ }^{13-15}$ The (re)discovery of many highly efficient and orthogonal chemistries, combined with the development of various functional group-tolerant living/ controlled polymerization techniques, has enormously expanded the scope of postpolymerization modification and resulted in an enormous increase in the use of this approach to synthesize functional polymers. ${ }^{16,17}$ Indeed, the modification of polymers could help tissue engineering in two ways: on the one hand improving material properties such as elasticity and degradation profiles and, on the other hand,

\footnotetext{
${ }^{1}$ Department of Chemistry, Materials and Chemical Engineering "Giulio Natta," Politecnico di Milano, Milan, Italy.

${ }^{2}$ Department of Experimental Trauma Surgery, Clinic for Trauma Surgery, Klinikum rechts der Isar, Technical University Munich, Munich, Germany.
} 
FIG. 1. Tissue engineering approach: the smart combination of cells and functional materials to replace damaged or missing parts of living tissues. Adapted with permission from Azagarsamy et al. ${ }^{5}$ Copyright 2013 American Chemical Society. Color images available online at www.liebertpub.com/tea

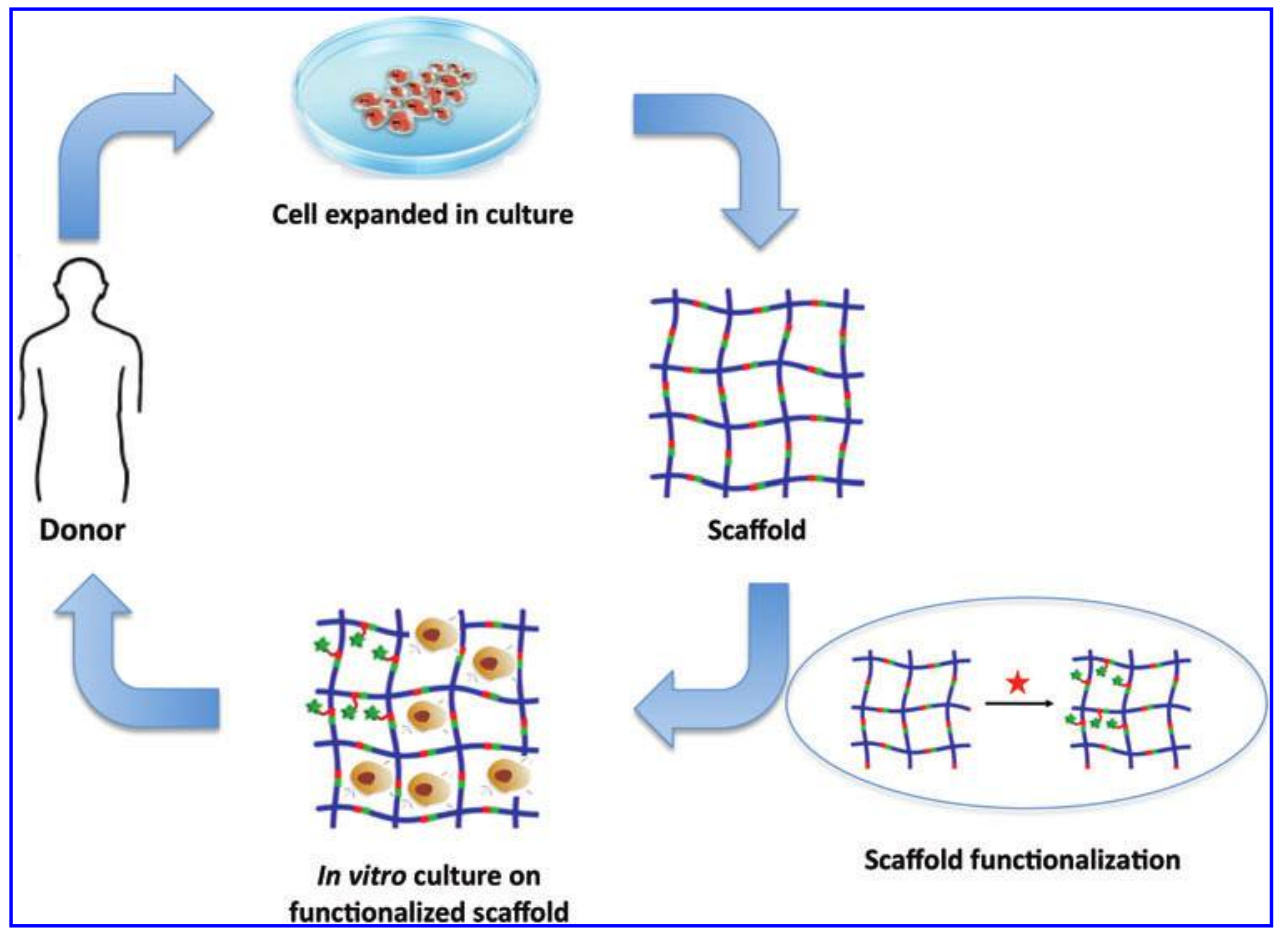

enriching the cell environment to be closer to the natural situation of the tissue to be regenerated. ${ }^{18,19}$ In particular, recent studies underlined the possibility to build time-related degradable scaffolds, ${ }^{20}$ hybrid (organic/inorganic) scaffolds, ${ }^{21}$ and materials able to increase cell viability and differentiation. $^{22}$

Hence, looking at the developments in this field, the aim of this review is to highlight the significant advances and breakthroughs and to provide the reader with a flavor of what has been accomplished and all the possibilities that are yet to be explored. Considering the high amount of publications of the last years, this approach promises to revolutionize the classic tissue engineering circle., 6 Figure 1 presents the tissue engineering circle redrawn, adding scaffold functionalization before cell seeding.

\section{Material Performances}

Functionalization in a scaffold design must be able to create porous structures to attain the desired mechanical function and mass transport (i.e., permeability and diffusion) properties, and to produce these structures within arbitrary and complex 3D anatomical shapes. The physical aspects of a scaffold design, as with polymer choice, depend largely on the final application. The scaffold is meant to provide the appropriate chemical, physical, and mechanical properties required for cell survival and tissue formation. Essentially, the polymeric scaffold is designed to define the cellular microenvironment (cell niche) required for optimal function. In particular, several modifications could be considered to improve scaffold native performances, adding advantages typical for other classes of materials. ${ }^{23-26}$ This is the case of functionalization to create hybrid (organic/inorganic) scaffolds. ${ }^{27}$ In bone tissue engineering, hydroxyapatite and calcium phosphates present high osteoconductivity, but low mechanical properties. ${ }^{28}$ In this direction, several research groups functionalized synthetic scaffolds (made of polylactic acid or polycaprolactone) with hydroxyapatite and calcium phosphate. ${ }^{29-35}$

In the same direction, Armentano et al. ${ }^{21}$ investigated the role of carbon nanotube incorporation on poly-L-lactic acidbased scaffolds: mechanical properties together with cell adhesion demonstrated an enhancement related to the introduction of inorganic nanotubes in organic compounds. The aim of this approach is to guarantee the advantages typical for polymers as biocompatibility, high design possibility, injectability, and degradability together with properties typical for inorganic compounds such as osteoconductivity. ${ }^{36,37}$ Hence, magnetic nanoparticles showed a high possibility to address targeting therapies and imaging that could be linked with polymer chains ${ }^{38,39}$ improving their performances.

Polymeric scaffolds and hydrogels are widely used for controlled drug delivery purposes with the aim to avoid under- and overdosing, while maintaining the drug level within a desired range for a long period. ${ }^{8}$ Despite the good results obtained in many applications, several problems are present due to the fact that drug release from 3D matrices is mostly driven by a pure diffusion mechanism, where free solutes very rapidly escape to the surrounding solution. In this direction, researchers are aiming to develop scaffolds that are able to delay release rates or allow multiple release kinetics, for example, different factors. Release rates of several compounds could be delayed using a cleavable spacer (i.e., binding peptide) that links peptides ${ }^{40-43}$ or vitamins ${ }^{44}$ with the polymeric chains of the scaffold. The possibility to deliver different drugs from a single device could be also realized by multilayer hydrogels ${ }^{45}$ and by the use of scaffolds linked with liposomes, where drugs could be loaded either within the matrix or within liposomes. ${ }^{46,47}$ Moreover, polymer functionalization could be used to improve 
mechanical properties: the most common approach is to combine synthetic and natural polymers to consider the advantages of both these systems. ${ }^{12}$ On one hand, synthetic polymers can be tuned in terms of composition, rate of degradation, mechanical and chemical properties. On the other hand, naturally derived polymers provide compositional uniqueness, such as stimulating a specific cellular response, which sometimes overrides the advantages of synthetic polymers. In this direction, Chen et al. ${ }^{48}$ and $\mathrm{Su}$ et al. ${ }^{49}$ modified polyester scaffolds with collagen. This particular family of scaffolds (polyesters) presents problems due to the low hydrophilicity that does not allow high cell ad- hesion and proliferation. ${ }^{50}$ To overcome these problems, these scaffolds could be functionalized in different ways ${ }^{51}$ using polydioxanone, ${ }^{52}$ polylysine, ${ }^{53}$ polyphosphazene, ${ }^{54}$ heparin, ${ }^{55}$ or inducing hydrophilicity by plasma treatment. ${ }^{56}$

From a material point of view, scaffold functionalization could also improve thermal resistance ${ }^{57}$ and mechanical properties to adapt materials to different medical needs ${ }^{58,59}$ together with the possibility to allow high material processability. ${ }^{60}$ Here, a detailed discussion should be reserved to degradability, one of the most important characteristics of biomaterials. In particular, biodegradable materials should not evoke a sustained inflammatory or toxic response upon

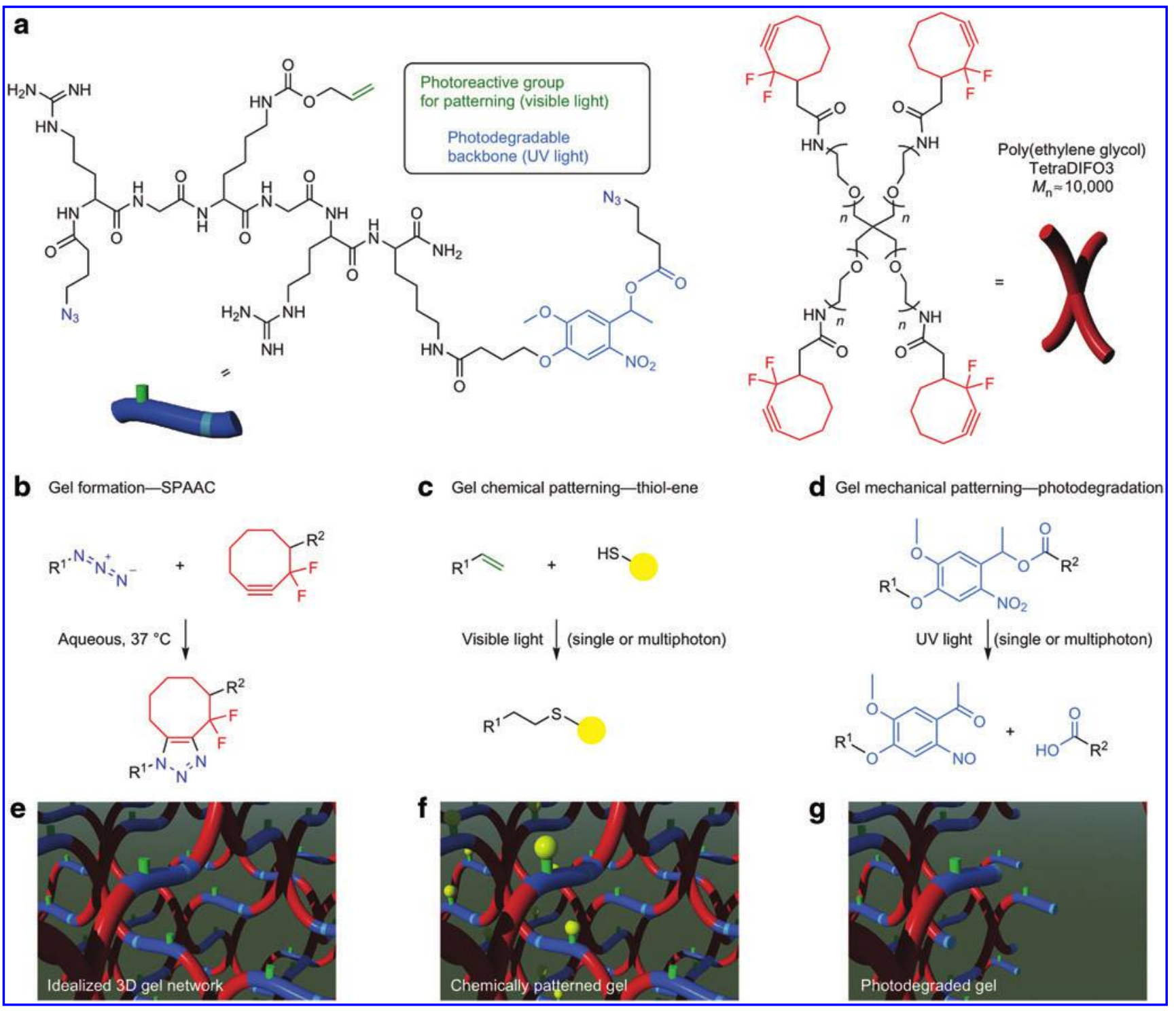

FIG. 2. Synthesis, photocoupling, and photodegradation for tuning chemical and physical properties of click-based hydrogels. (a, b) Click-functionalized macromolecular precursors (PEG-tetraDIFO3 and bis(azide)-functionalized polypeptides) form a three-dimensional ideal hydrogel structure (a) by means of a step-growth polymerization mechanism through the SPAAC reaction (b). (c) In the presence of visible light $(\lambda=490-650$ or $860 \mathrm{~nm})$, thiol-containing biomolecules are covalently affixed to pendant vinyl functionalities throughout the hydrogel network through the thiol-ene reaction. (d) A nitrobenzyl ether moiety within the backbone of the polymer network undergoes photocleavage in the presence of single or multiphoton ultraviolet light $(\lambda=365$ or $740 \mathrm{~nm})$ that results in photodegradation of the network. Schematics of the formed SPAAC-based idealized gel (e), the network after thiol-ene functionalization (f) and the material after photodegradation (g). (Adapted from DeForest $e t$ al. ${ }^{20}$ [with permission from the Nature Publishing Group]). Color images available online at www.liebertpub.com/tea 
implantation in the body together with having an acceptable shelf life. The degradation time of the material should match the healing or regeneration process and the degradation products should be nontoxic, and able to get metabolized and cleared from the body. ${ }^{61}$ Chien et al. ${ }^{62}$ added disulfidecontaining crosslinkers to form a biodegradable carboxybetaine hydrogel, which can be self-degraded as cells grow or degraded in an accelerating way by means of adding a cysteine-contained medium to NIH 3T3 cells.

Another approach was the one developed by the Anseth group, ${ }^{20,63}$ where step-growth networks are formed rapidly through a copper-free, azide-alkyne click chemistry between tetrafunctional poly(ethylene glycol) molecules and difunctionalized synthetic polypeptides. A sequential photochemically activated thiol-ene chemistry allows subsequent functionalization of the network through reaction with pendant alkene moieties on the peptide (Fig. 2). Because the thiol-ene reaction is light driven, the degree of modification is directly related to the dosage of light delivered to the system. Functional groups incorporated into this class of materials are able to produce networks that are capable of degrading in the presence of light, allowing the effects of physical material cues on cell function to be probed.

\section{Biological Performances}

The scaffold, by definition, is a temporary supporting structure for growing cells and tissues. It is also called synthetic ECM and plays a critical role in supporting cells. These cells then undergo proliferation, migration, and differentiation in three dimensions, which lead to the formation of a specific tissue with appropriate functions as would be found in the human body. ${ }^{1}$ Cells primarily interact with scaffolds through antigens on their surface and chemical groups (ligands) on the material surface. ${ }^{64}$

Cell attachment is strongly affected by the biophysical nature of the ligand. Hence, the ability to design biomaterial substrates with known and quantifiable densities of adhesion molecules makes it possible to manipulate cell behavior by the correct preparation of the substrate. Recent literature supports the idea that density ${ }^{65-67}$ of a ligand is a fundamental scaffold requirement. Ligand density is mainly influenced by the specific surface area of pores to which cells can adhere. Pores thus need to be of an optimal size to allow cells to migrate into the structure, but do not need to have contact. The cells become eventually bound to the ligands within the scaffold, but the ligands need to be small enough

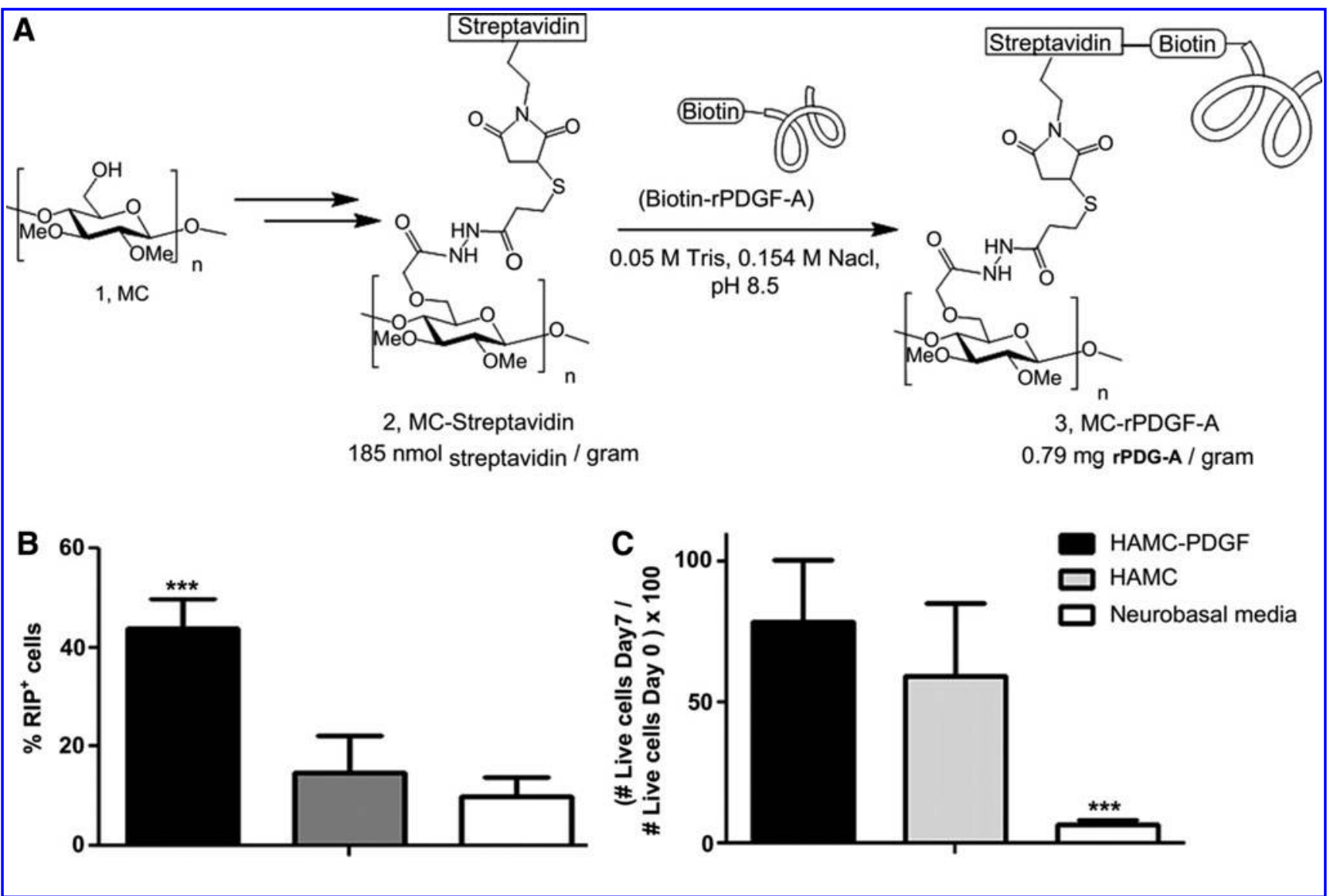

FIG. 3. (A) Chemical conjugation of biotin-rPDGF-A to MC. MC (1) was chemically modified to covalently conjugate maleimide streptavidin (B, C) in vitro characterization of neural stem cells (SCs) in various culture conditions. Cells were premixed into the hyaluronic acid-methylcellulose (HAMC) hydrogel or in neurobasal media and then plated at $4 \times 10^{4}$ cells $/$ well into an eight-well chamber slide for 7 days. (B) HAMC-platelet-derived growth factor (PDGF) promotes oligodendrocyte differentiation and shows a higher percentage of RIP 6 cells compared to cells cultured in HAMC alone (gray) or in neurobasal media alone (white). (C) Cell viability of SCs, as determined by live/dead assay. Viability of SCs cultured in neurobasal media was significantly lower than cells cultured in HAMC-PDGF or HAMC alone. ${ }^{* *} \mathrm{p}<0.001$. (Adopted from Mothe et al. ${ }^{22}$ [with permission from Elsevier]). 
to establish a sufficiently high-specific surface, leading to a minimal ligand density to allow efficient binding of a critical number of cells to the scaffold. Therefore, for any scaffold, a critical range of pore sizes exist, which may vary depending on the cell type used and tissue being engineered. Moreover, porous interconnectivity is equally important in the same sense for cells to be able to penetrate the scaffold. To improve cell attachment to the scaffold, other parameters also should be taken into account like stiffness, ${ }^{68}$ cell phenotype ${ }^{69}$ and nature of ligand. ${ }^{70}$ Scaffolds synthesized from natural extracellular materials (e.g., collagen) naturally possess these ligands in the form of Arg-Gly-Asp (RGD) binding sequences, whereas scaffolds made from synthetic materials may require deliberate incorporation of these ligands through functionalization. ${ }^{12,43,71}$ If these ligands are not present in the polymers themselves, they must be incorporated to be able to have the cells attached. In this framework, research developed a large amount of strategies for scaffold functionalization. ${ }^{5}$ Of note, differences should be considered between two-dimensional (2D) scaffolds, where cells are cultured onto the matrix (superficial functionalization) and 3D hydrogels, where cells are included within a 3D polymeric network (bulk functionalization). In the first case, researchers provide different possibilities to improve cell adhesion onto polyester scaffolds, mainly improving their hydrophilicity. ${ }^{72}$ In particular, polycaprolactone and polyL-lactic acid-based scaffolds were modified with gelatin, ${ }^{73}$ RGD peptides, ${ }^{74-76}$ and collagen I. ${ }^{77}$ Moreover, LopezPerez et al. ${ }^{78}$ developed the possibility to functionalize the surface of polycaprolactone scaffolds with surface grafting of sulfonic or phosphonic groups through plasma-induced polymerization of vinyl sulfone: the presence of these anionic functional groups can modulate cell adhesion mediated through the adsorbed proteins present in the culture medium. Functionalization of implantable scaffolds (2D) is important to improve their performances, but the topic will become even more fundamental if we consider 3D injectable composites of cells with PEG or polysaccharides. ${ }^{79,80}$ Indeed, material adhesion properties should be improved functionalizing them with RGD, ${ }^{81-84}$ cysteine, ${ }^{85}$ collagen-like proteins, ${ }^{86}$ heparin, ${ }^{87,88}$ laminin ${ }^{89}$ lysine, ${ }^{90}$ and streptavidin. ${ }^{91}$

In several cell therapies, materials should not only guarantee high cell-material adhesion and viability after having been implanted, but also sufficient cell orientation to improve medical success. ${ }^{92,93}$ This is, for instance, the case in nerve regeneration, where modified substrates often provide better environments for neurite outgrowth. Multiwalled carbon nanotube-coated electrospun poly (1-lactic acid-cocaprolactone) nanofibers improved the neurite outgrowth of rat dorsal root ganglia neurons and focal adhesion kinase expression of PC-12 cells. ${ }^{94}$ The high ability of carbon nanotubes to orient cell culture was also studied by Luo et al., ${ }^{95}$ where electrospun cellulose acetate nanofibers were assembled with positively charged chitosan and negatively charged multiwalled carbon nanotubes through a layer-bylayer self-assembly technique.

Another key challenge in tissue engineering is overcoming cell death in the scaffold interior due to the limited diffusion of oxygen and nutrients therein. Odedra et al..$^{96}$ hypothesized and demonstrated that immobilizing a gradient of a growth/ survival factor from the periphery to the center of a porous
Table 1. Principal Functionalization Strategies Related to Material Properties

\begin{tabular}{|c|c|}
\hline Material properties & Functionalization \\
\hline Adhesiveness to cells & $\begin{array}{l}\text { Carbon nanotubes } \\
\text { Collagen }^{48,49,73} \\
\text { Glucagon-like peptide }^{85} \\
\text { Growth factor }^{79,96,110} \\
\text { Heparin } \\
\text { La,87,88 } \\
\text { Muminin }^{89} \\
\text { Polydioxanol adhesive proteins }^{102,103} \\
\text { Polylysine }^{53,90} \\
\text { Polyphosphazene }^{54} \\
\text { Resveratrol }^{106} \\
\text { RGD peptide }^{74-76,81-84,97-101} \\
\text { Silanol group }^{107} \\
\text { Sulfonic group }^{78} \\
\text { Streptavidin }^{22}\end{array}$ \\
\hline Degradability & $\begin{array}{l}\text { Disulfide crosslinkers }{ }^{62} \\
\text { RGD peptide }^{11,20,63}\end{array}$ \\
\hline $\begin{array}{l}\text { Imaging capacity } \\
\text { Osteoconductivity }\end{array}$ & $\begin{array}{l}\text { Magnetic nanoparticles } \\
\text { Calcium phosphate }^{33-39} \\
\text { Carbon nanotubes }^{21} \\
\text { Hydroxyapatite }^{29-32}\end{array}$ \\
\hline $\begin{array}{l}\text { Protein/drug retention } \\
\text { and release }\end{array}$ & $\begin{array}{l}\text { Chemical linkers } \\
\text { Layer polymers }^{40-44} \\
\text { Liposomes }^{46}\end{array}$ \\
\hline
\end{tabular}

scaffold would guide endothelial cells into the interior of the scaffold, thus overcoming a necrotic core.

Moreover, functionalized scaffolds, once being cultured with stem cells (SCs), are able to create an environment favorable for their differentiation. In this sense, RGD peptides were used for human mesenchymal SCs, ${ }^{11,20,97,98}$ retinal $^{99,100}$ and neural SCs ${ }^{101}$ and mussel adhesive peptides for preosteoblast cells ${ }^{102}$ and human adipose tissue-derived SCs. ${ }^{103}$ Furthermore, streptavidin modification is able to induce neural SC ${ }^{22,104,105}$ differentiation: Mothe et al. ${ }^{22}$ encapsulated neural SCs either in unmodified (hyaluronic acid-methylcellulose [HAMC]) and in functionalized (HAMC-platelet derived growth factor/[PDGF], Fig. 3A) hydrogels for 7 days. HAMC-PDGF (black) significantly increased the percentage of oligodendrocytes and live cells if compared to cells cultured in unmodified HAMC (gray) or in neurobasal media (white) alone (Fig. 3B, C). In bone tissue engineering, polycaprolactone-based scaffolds, were functionalized with resveratrol, ${ }^{106}$ silanol, and growth factors ${ }^{107-109}$ and when implanted in vivo and cultured with adipose-derived SCs, are able to promote the expression of neovascularization mediators, which may help overcome the nutrition deficit in the inner part of the scaffold. ${ }^{110}$ Diffusion of nutrients is able up to distances of maximum $200 \mu \mathrm{m}$.

In summary, in Table 1, the principal functionalization strategies are related to the material properties they are aiming to improve.

\section{Conclusions and Future Directions}

The creation of complex tissues and organs is the ultimate goal of tissue engineering. The main aim of this review is to provide information about the methods used for preparing functional scaffolds. Following this approach, modified polymer scaffolds could improve their performances in terms 
of mechanical properties, degradation kinetics, cell adhesion, and differentiation with respect to the unmodified ones. Despite recent advances in the development of functional biomaterials, several challenges still remain, including the dynamic cellular microenvironment in the design of scaffolds. Novel scaffolds that are able to allow simultaneous spatial and temporal resolution, being also cell responsive, promise to be a great challenge for the future. In particular, the possibility to modulate different scaffold areas with different properties is the key point that should be addressed. Following this strategy, different cell types can grow together in a unique scaffold creating mutual networks and thereby providing a more biomimetic environment. Engineered polymers can be used as a platform to better mimic the cell niche, allowing for multiple stimuli and many cell types to be explored individually or in combination. Regarding in vivo applications, innovative biomaterials should overcome the current problems of cell survival and integration after implantation or injection.

\section{Acknowledgments}

The authors would like to thank Fritz Seidl M.A. for proofreading this manuscript.

\section{Disclosure Statement}

No competing financial interests exist.

\section{References}

1. Hildner, F., Albrecht, C., Gabriel, C., Redl, H., and van Griensven, M. State of the art and future perspectives of articular cartilage regeneration: a focus on adipose-derived stem cells and platelet-derived products. I Tissue Eng Regen Med 5, E36, 2011.

2. Luo, X.S., Liu, Y., Zhang, Z.Y., Tao, R., He, A.J., Yin, Z.Q., Li, D., Zhang, W.J., Liu, W., Cao, Y.L., and Zhou, G.D. Long-term functional reconstruction of segmental tracheal defect by pedicled tissue-engineered trachea in rabbits. Biomaterials 34, 3336, 2013.

3. Aizawa, Y., Owen, S.C., and Shoichet, M.S. Polymers used to influence cell fate in 3D geometry: new trends. Prog Polym Sci 37, 645, 2012.

4. Perale, G., Rossi, F., Santoro, M., Peviani, M., Papa, S., Llupi, D., Torriani, P., Micotti, E., Previdi, S., Cervo, L., Sundstrom, E., Boccaccini, A.R., Masi, M., Forloni, G., and Veglianese, P. Multiple drug delivery hydrogel system for spinal cord injury repair strategies. J Control Release 159, 271, 2012.

5. Azagarsamy, M.A., and Anseth, K.S. Bioorthogonal click chemistry: an indispensable tool to create multifaceted cell culture scaffolds. Acs Macro Letters 2, 5, 2013.

6. Atala, R., Langer, R., Thomson, J., and Nerem, R. Principles of Regenerative Medicine. Burlington, MA: Academic Press, 2008.

7. Langer, R. Perspectives and challenges in tissue engineering and regenerative medicine. Adv Mater 21, 3235, 2009.

8. Slaughter, B.V., Khurshid, S.S., Fisher, O.Z., Khademhosseini, A., and Peppas, N.A. Hydrogels in regenerative medicine. Adv Mater 21, 3307, 2009.

9. Kirschner, C.M., and Anseth, K.S. Hydrogels in healthcare: from static to dynamic material microenvironments. Acta Mater 61, 931, 2013.

10. Nicolas, J., Mura, S., Brambilla, D., Mackiewicz, N., and Couvreur, P. Design, functionalization strategies and bio- medical applications of targeted biodegradable/biocompatible polymer-based nanocarriers for drug delivery. Chem Soc Rev 42, 1147, 2013.

11. Anderson, S.B., Lin, C.C., Kuntzler, D.V., and Anseth, K.S. The performance of human mesenchymal stem cells encapsulated in cell-degradable polymer-peptide hydrogels. Biomaterials 32, 3564, 2011.

12. Shoichet, M.S. Polymer scaffolds for biomaterials applications. Macromolecules 43, 581, 2010.

13. Ossipov, D.A., Piskounova, S., Varghese, O.P., and Hilborn, J. Functionalization of hyaluronic acid with chemoselective groups via a disulfide-based protection strategy for in situ formation of mechanically stable hydrogels. Biomacromolecules 11, 2247, 2010.

14. Subramani, C., Cengiz, N., Saha, K., Gevrek, T.N., Yu, X., Jeong, Y., Bajaj, A., Sanyal, A., and Rotello, V.M. Direct fabrication of functional and biofunctional nanostructures through reactive imprinting. Adv Mater 23, 3165, 2011.

15. Sletten, E.M., and Bertozzi, C.R. From mechanism to mouse: a tale of two bioorthogonal reactions. Accounts Chem Res 44, 666, 2011.

16. Durmaz, H., Sanyal, A., Hizal, G., and Tunca, U. Double click reaction strategies for polymer conjugation and postfunctionalization of polymers. Polym Chem 3, 825, 2012.

17. Kade, M.J., Burke, D.J., and Hawker, C.J. The power of thiol-ene chemistry. J Polym Sci Part A Polym Chem 48, 743, 2010.

18. Binder, W.H., and Sachsenhofer, R. 'Click' chemistry in polymer and materials science. Macromol Rapid Comm 28, 15, 2007.

19. Theato, P., and Klok, H.A. Functional Polymers by PostPolymerization Modification. Weinheim, Germany: WileyVCH, 2012.

20. DeForest, C.A., and Anseth, K.S. Cytocompatible clickbased hydrogels with dynamically tunable properties through orthogonal photoconjugation and photocleavage reactions. Nat Chem 3, 925, 2011.

21. Armentano, I., Marinucci, L., Dottori, M., Balloni, S., Fortunati, E., Pennacchi, M., Becchetti, E., Locci, P., and Kenny, J.M. Novel Poly(L-lactide) PLLA/SWNTs Nanocomposites for biomedical applications: material characterization and biocompatibility evaluation. J Biomat Sci Polym E 22, 541, 2011.

22. Mothe, A.J., Tam, R.Y., Zahir, T., Tator, C.H., and Shoichet, M.S. Repair of the injured spinal cord by transplantation of neural stem cells in a hyaluronan-based hydrogel. Biomaterials 34, 3775, 2013.

23. Tyson, T., Malberg, S., Watz, V., Finne-Wistrand, A., and Albertsson, A.C. Functional and highly porous scaffolds for biomedical applications. Macromol Biosci 11, 1432, 2011.

24. Wang, R., Chen, W., Meng, F.H., Cheng, R., Deng, C., Feijen, J., and Zhong, Z.Y. Unprecedented access to functional biodegradable polymers and coatings. Macromolecules 44, 6009, 2011.

25. Ward, J., Kelly, J., Wang, W.X., Zeugolis, D.I., and Pandit, A. Amine functionalization of collagen matrices with multifunctional polyethylene glycol systems. Biomacromolecules 11, 3093, 2010.

26. Morelli, A., and Chiellini, F. Ulvan as a new type of biomaterial from renewable resources: functionalization and hydrogel preparation. Macromol Chem Phys 211, 821, 2010.

27. Leonor, I.B., Rodrigues, G.T., Gomes, M.E., and Reis, R.L. In situ functionalization of wet-spun fibre meshes for bone tissue engineering. J Tissue Eng Regen Med 5, 104, 2011. 
28. Wei, G.B., and Ma, P.X. Structure and properties of nanohydroxyapatite/polymer composite scaffolds for bone tissue engineering. Biomaterials 25, 4749, 2004.

29. Bach, L.G., Rafiqul Islam, M., Vo, T.S., Kim, S.K., and Lim, K.T. Poly(allyl methacrylate) functionalized hydroxyapatite nanocrystals via the combination of surface-initiated RAFT polymerization and thiol-ene protocol: A potential anticancer drug nanocarrier. I Colloid Interf Sci 394, 132, 2013.

30. Dyke, J.C., Knight, K.J., Zhou, H.X., Chiu, C.K., Ko, C.C., and You, W. An investigation of siloxane cross-linked hydroxyapatite-gelatin/copolymer composites for potential orthopedic applications. J Mater Chem 22, 22888, 2012.

31. Jaiswal, A.K., Kadam, S.S., Soni, V.P., and Bellare, J.R. Improved functionalization of electrospun PLLA/gelatin scaffold by alternate soaking method for bone tissue engineering. Appl Surf Sci 268, 477, 2013.

32. Phipps, M.C., Xu, Y.Y., and Bellis, S.L. Delivery of plateletderived growth factor as a chemotactic factor for mesenchymal stem cells by bone-mimetic electrospun scaffolds. PLos One 7, e40831, 2012.

33. Dorj, B., Kim, M.K., Won, J.E., and Kim, H.W. Functionalization of poly(caprolactone) scaffolds by the surface mineralization for use in bone regeneration. Mater Lett 65, 3559, 2011.

34. Gkioni, K., Leeuwenburgh, S.C.G., Douglas, T.E.L., Mikos, A.G., and Jansen, J.A. Mineralization of hydrogels for bone regeneration. Tissue Eng Part B Rev 16, 577, 2010.

35. Kim, J.H., Kim, T.H., Jin, G.Z., Park, J.H., Yun, Y.R., Jang, J.H., and Kim, H.W. Mineralized poly(lactic acid) scaffolds loading vascular endothelial growth factor and the in vivo performance in rat subcutaneous model. J Biomed Mater Res A 101A, 1447, 2013.

36. Tan, W., Twomey, J., Guo, D.J., Madhavan, K., and Li, M. Evaluation of nanostructural, mechanical, and biological properties of collagen-nanotube composites. IEEE Trans Nanobiosci 9, 111, 2010.

37. Venkatesan, J., Qian, Z.J., Ryu, B., Kumar, N.A., and Kim, S.K. Preparation and characterization of carbon nanotubegrafted-chitosan-natural hydroxyapatite composite for bone tissue engineering. Carbohyd Polym 83, 569, 2011.

38. Li, M., Neoh, K.G., Wang, R., Zong, B.Y., Tan, B.Y., and Kang, E.T. Methotrexate-conjugated and hyperbranched polyglycerol-grafted $\mathrm{Fe} 3 \mathrm{O} 4$ magnetic nanoparticles for targeted anticancer effects. Eur J Pharm Sci 48, 111, 2013.

39. Pasqui, D., Atrei, A., Giani, G., De Cagna, M., and Barbucci, R. Metal oxide nanoparticles as cross-linkers in polymeric hybrid hydrogels. Mater Lett 65, 392, 2011.

40. Vulic, K., and Shoichet, M.S. Tunable growth factor delivery from injectable hydrogels for tissue engineering. I Am Chem Soc 134, 882, 2012.

41. Chen, J., Zhou, B., Li, Q., Jun, O.Y., Kong, J.M., Zhong, W., and Xing, M.M.Q. PLLA-PEG-TCH-labeled bioactive molecule nanofibers for tissue engineering. Int J Nanomed 6, 2533, 2011.

42. Gilmore, L., Rimmer, S., McArthur, S.L., Mittar, S., Sun, D.C., and MacNeil, S. Arginine functionalization of hydrogels for heparin bindingua supramolecular approach to developing a pro-angiogenic biomaterial. Biotechnol Bioeng 110, 296, 2013.

43. Ouasti, S., Kingham, P.J., Terenghi, G., and Tirelli, N. The CD44/integrins interplay and the significance of receptor binding and re-presentation in the uptake of RGDfunctionalized hyaluronic acid. Biomaterials 33, 1120, 2012.
44. Wang, X.Q., and Kaplan, D.L. Functionalization of silk fibroin with neutravidin and biotin. Macromol Biosci 11, 100, 2011.

45. Shih, H., Fraser, A.K., and Lin, C.C. Interfacial thiol-ene photoclick reactions for forming multilayer hydrogels. Acs Appl Mater Inter 5, 1673, 2013.

46. Zhang, H.Y., Cleymand, F., Noel, C., Kahn, C.J.F., Linder, M., Dahoun, A., Henrion, G., and Arab-Tehrany, E. Effects of Ar-H-2-N-2 microwave plasma on chitosan and its nanoliposomes blend thin films designed for tissue engineering applications. Carbohyd Polym 93, 401, 2013.

47. Rossi, F., Perale, G., Papa, S., Forloni, G., and Veglianese, P. Current options for drug delivery to the spinal cord. Expert Opin Drug Deliv 10, 385, 2013.

48. Chen, G., Xia, Y., Lu, X.L., Zhou, X.F., Zhang, F.M., and Gu, $\mathrm{N}$. Effects of surface functionalization of PLGA membranes for guided bone regeneration on proliferation and behavior of osteoblasts. J Biomed Mater Res A 101A, 44, 2013.

49. Su, Y., Su, Q.Q., Liu, W., Lim, M., Venugopal, J.R., Mo, X.M., Ramakrishna, S., Al-Deyab, S.S., and El-Newehy, M. Controlled release of bone morphogenetic protein 2 and dexamethasone loaded in core-shell PLLACL-collagen fibers for use in bone tissue engineering. Acta Biomater 8, 763, 2012.

50. Gentilini, C., Dong, Y.X., May, J.R., Goldoni, S., Clarke, D.E., Lee, B.H., Pashuck, E.T., and Stevens, M.M. Functionalized poly(gamma-Glutamic Acid) fibrous scaffolds for tissue engineering. Adv Healthc Mater 1, 308, 2012.

51. Ghasemi-Mobarakeh, L., Prabhakaran, M.P., Morshed, M., Nasr-Esfahani, M.H., and Ramakrishna, S. Bio-functionalized PCL nanofibrous scaffolds for nerve tissue engineering. Mater Sci Eng C Mater Biol Appl 30, 1129, 2010.

52. Cont, L., Grant, D., Scotchford, C., Todea, M., and Popa, C. Composite PLA scaffolds reinforced with PDO fibers for tissue engineering. J Biomater Appl 27, 707, 2013.

53. Yamanlar, S., Sant, S., Boudou, T., Picart, C., and Khademhosseini, A. Surface functionalization of hyaluronic acid hydrogels by polyelectrolyte multilayer films. Biomaterials 32, 5590, 2011.

54. Peach, M.S., Kumbar, S.G., James, R., Toti, U.S., Balasubramaniam, D., Deng, M., Ulery, B., Mazzocca, A.D., McCarthy, M.B., Morozowich, N.L., Allcock, H.R., and Laurencin, C.T. Design and optimization of polyphosphazene functionalized fiber matrices for soft tissue regeneration. J Biomed Nanotechnol 8, 107, 2012.

55. de Mulder, E.L.W., Hannink, G., Koens, M.J.W., Lowik, D., Verdonschot, N., and Buma, P. Characterization of polyurethane scaffold surface functionalization with diamines and heparin. J Biomed Mater Res Part A 101A, 919, 2013.

56. Cheng, Q., Lee, B.L.P., Komvopoulos, K., Yan, Z.Q., and Li, S. Plasma surface chemical treatment of electrospun poly(Llactide) microfibrous scaffolds for enhanced cell adhesion, growth, and infiltration. Tissue Eng Part A 19, 1188, 2013.

57. Huerta-Angeles, G., Smejkalova, D., Chladkova, D., Ehlova, T., Buffa, R., and Velebny, V. Synthesis of highly substituted amide hyaluronan derivatives with tailored degree of substitution and their crosslinking via click chemistry. Carbohyd Polym 84, 1293, 2011.

58. Wray, L.S., Rnjak-Kovacina, J., Mandal, B.B., Schmidt, D.F., Gil, E.S., and Kaplan, D.L. A silk-based scaffold platform with tunable architecture for engineering critically-sized tissue constructs. Biomaterials 33, 9214, 2012.

59. You, Z.W., Bi, X.P., Fan, X.Q., and Wang, Y.D. A functional polymer designed for bone tissue engineering. Acta Biomater 8, 502, 2012. 
60. Raphel, J., Parisi-Amon, A., and Heilshorn, S.C. Photoreactive elastin-like proteins for use as versatile bioactive materials and surface coatings. J Mater Chem 22, 19429, 2012.

61. Nair, L.S., and Laurencin, C.T. Biodegradable polymers as biomaterials. Prog Polym Sci 32, 762, 2007.

62. Chien, H.W., Tsai, W.B., and Jiang, S.Y. Direct cell encapsulation in biodegradable and functionalizable carboxybetaine hydrogels. Biomaterials 33, 5706, 2012.

63. DeForest, C.A., Sims, E.A., and Anseth, K.S. Peptide-functionalized click hydrogels with independently tunable mechanics and chemical functionality for 3D cell culture. Chem Mater 22, 4783, 2010.

64. Lam, M.T., and Longaker, M.T. Comparison of several attachment methods for human iPS, embryonic and adiposederived stem cells for tissue engineering. J Tissue Eng Regen Med 6, s80, 2012.

65. Ward, M.D., Dembo, M., and Hammer, D.A. Kinetics of cell detachment-effect of ligand density. Ann Biomed Eng 23, 322, 1995.

66. Tzeranis, D.S., Roy, A., So, P.T.C., and Yannas, I.V. An optical method to quantify the density of ligands for cell adhesion receptors in three-dimensional matrices. I R Soc Interface 7, S649, 2010.

67. Deeg, J.A., Louban, I., Aydin, D., Selhuber-Unkel, C., Kessler, H., and Spatz, J.P. Impact of local versus global ligand density on cellular adhesion. Nano Lett 11, 1469, 2011.

68. Engler, A., Bacakova, L., Newman, C., Hategan, A., Griffin, M., and Discher, D. Substrate compliance versus ligand density in cell on gel responses. Biophys J 86, 617, 2004.

69. Kong, H.J., Boontheekul, T., and Mooney, D.J. Quantifying the relation between adhesion ligand-receptor bond formation and cell phenotype. Proc Natl Acad Sci U S A 103, 18534, 2006.

70. Ronn, L.C.B., Olsen, M., Ostergaard, S., Kiselyov, V., Berezin, V., Mortensen, M.T., Lerche, M.H., Jensen, P.H., Soroka, V., Saffells, J.L., Doherty, P., Poulsen, F.M., Bock, E., and Holm, A. Identification of a neuritogenic ligand of the neural cell adhesion molecule using a combinatorial library of synthetic peptides. Nat Biotechnol 17, 1000, 1999.

71. Borcard, F., Staedler, D., Comas, H., Juillerat, F.K., Sturzenegger, P.N., Heuberger, R., Gonzenbach, U.T., Juillerat-Jeanneret, L., and Gerber-Lemaire, S. Chemical functionalization of bioceramics to enhance endothelial cells adhesion for tissue engineering. I Med Chem 55, 7988, 2012.

72. Pertici, G., Muller, M., and Perale, G. Bioresorbable bioactive matrix for bone regeneration. Tissue Eng Part A 16, A10,2010

73. Desmet, T., Poleunis, C., Delcorte, A., and Dubruel, P. Double protein functionalized poly-epsilon-caprolactone surfaces: in depth ToF-SIMS and XPS characterization. I Mater Sci Mater Med 23, 293, 2012.

74. Gloria, A., Causa, F., Russo, T., Battista, E., Della Moglie, R., Zeppetelli, S., De Santis, R., Netti, P.A., and Ambrosio, L. Three-dimensional poly(epsilon-caprolactone) bioactive scaffolds with controlled structural and surface properties. Biomacromolecules 13, 3510, 2012.

75. Losel, R., Grafahrend, D., Moller, M., and Klee, D. Bioresorbable electrospun fibers for immobilization of thiolcontaining compounds. Macromol Biosci 10, 1177, 2011.

76. Perez, E.R., Cruz, D.M.G., Monros, M.C.A., Gomez-Pinedo, U., Pradas, M.M., and Ivirico, J.L.E. Polymer chains incorporating caprolactone and arginine-glycine-aspartic acid functionalities: synthesis, characterization and biological response in vitro of the Schwann cell. J Bioact Compat Pol 28, 50, 2013.

77. Schofer, M.D., Tunnermann, L., Kaiser, H., Roessler, P.P., Theisen, C., Heverhagen, J.T., Hering, J., Voelker, M., Agarwal, S., Efe, T., Fuchs-Winkelmann, S., and Paletta, J.R.J. Functionalisation of PLLA nanofiber scaffolds using a possible cooperative effect between collagen type I and BMP-2: impact on colonization and bone formation in vivo. J Mater Sci Mater Med 23, 2227, 2012.

78. Lopez-Perez, P.M., da Silva, R.M.P., Sousa, R.A., Pashkuleva, I., and Reis, R.L. Plasma-induced polymerization as a tool for surface functionalization of polymer scaffolds for bone tissue engineering: an in vitro study. Acta Biomater 6, 3704, 2010.

79. Rahman, N., Purpura, K.A., Wylie, R.G., Zandstra, P.W., and Shoichet, M.S. The use of vascular endothelial growth factor functionalized agarose to guide pluripotent stem cell aggregates toward blood progenitor cells. Biomaterials 31, 8262, 2010.

80. Hume, P.S., Bowman, C.N., and Anseth, K.S. Functionalized PEG hydrogels through reactive dip-coating for the formation of immunoactive barriers. Biomaterials 32, 6204, 2011.

81. Gould, S.T., Darling, N.J., and Anseth, K.S. Small peptide functionalized thiol-ene hydrogels as culture substrates for understanding valvular interstitial cell activation and de novo tissue deposition. Acta Biomater 8, 3201, 2012.

82. Lin, C.C., Metters, A.T., and Anseth, K.S. Functional PEGpeptide hydrogels to modulate local inflammation induced by the pro-inflammatory cytokine TNF alpha. Biomaterials 30, 4907, 2009.

83. Panda, J.J., Dua, R., Mishra, A., Mittra, B., and Chauhan, V.S. 3D cell growth and proliferation on a RGD functionalized nanofibrillar hydrogel based on a conformationally restricted residue containing dipeptide. Acs Appl Mater Inter 2, 2839, 2010.

84. Tam, R.Y., Cooke, M.J., and Shoichet, M.S. A covalently modified hydrogel blend of hyaluronan-methyl cellulose with peptides and growth factors influences neural stem/ progenitor cell fate. J Mater Chem 22, 19402, 2012.

85. Lin, C.C., and Anseth, K.S. Glucagon-like peptide-1 functionalized PEG hydrogels promote survival and function of encapsulated pancreatic beta-cells. Biomacromolecules 10, 2460, 2009.

86. Cosgriff-Hernandez, E., Hahn, M.S., Russell, B., Wilems, T., Munoz-Pinto, D., Browning, M.B., Rivera, J., and Hook, M. Bioactive hydrogels based on Designer Collagens. Acta Biomater 6, 3969, 2010.

87. Gumusderelioglu, M., and Aday, S. Heparin-functionalized chitosan scaffolds for bone tissue engineering. Carbohyd Res 346, 606, 2011.

88. Jiang, T., Khan, Y., Nair, L.S., Abdel-Fattah, W.I., and Laurencin, C.T. Functionalization of chitosan/poly(lactic acid-glycolic acid) sintered microsphere scaffolds via surface heparinization for bone tissue engineering. J Biomed Mater Res A 93A, 1193, 2010.

89. Brandl, F.P., Seitz, A.K., Tessmar, J.K.V., Blunk, T., and Gopferich, A.M. Enzymatically degradable poly(ethylene glycol) based hydrogels for adipose tissue engineering. Biomaterials 31, 3957, 2010.

90. Liu, Y.X., and Chan-Park, M.B. A biomimetic hydrogel based on methacrylated dextran-graft-lysine and gelatin for 3D smooth muscle cell culture. Biomaterials 31, 1158, 2010. 
91. Altin, H., Kosif, I., and Sanyal, R. Fabrication of "Clickable" hydrogels via dendron-polymer conjugates. Macromolecules 43, 3801, 2010.

92. Breukers, R.D., Gilmore, K.J., Kita, M., Wagner, K.K., Higgins, M.J., Moulton, S.E., Clark, G.M., Officer, D.L., Kapsa, R.M.I., and Wallace, G.G. Creating conductive structures for cell growth: growth and alignment of myogenic cell types on polythiophenes. I Biomed Mater Res A 95A, 256, 2010.

93. Richter, C., Reinhardt, M., Giselbrecht, S., Leisen, D., Trouillet, V., Truckenmuller, R., Blau, A., Ziegler, C., and Welle, A. Spatially controlled cell adhesion on three-dimensional substrates. Biomed Microdevices 12, 787, 2010.

94. Jin, G.Z., Kim, M., Shin, U.S., and Kim, H.W. Neurite outgrowth of dorsal root ganglia neurons is enhanced on aligned nanofibrous biopolymer scaffold with carbon nanotube coating. Neurosci Lett 501, 10, 2011.

95. Luo, Y., Wang, S.G., Shen, M.W., Qi, R.L., Fang, Y., Guo, R., Cai, H.D., Cao, X.Y., Tomas, H., Zhu, M.F., and Shi, X.Y. Carbon nanotube-incorporated multilayered cellulose acetate nanofibers for tissue engineering applications. Carbohyd Polym 91, 419, 2013.

96. Odedra, D., Chiu, L.L.Y., Shoichet, M., and Radisic, M. Endothelial cells guided by immobilized gradients of vascular endothelial growth factor on porous collagen scaffolds. Acta Biomater 7, 3027, 2011.

97. DeForest, C.A., Polizzotti, B.D., and Anseth, K.S. Sequential click reactions for synthesizing and patterning three-dimensional cell microenvironments. Nat Mater 8, 659, 2009.

98. Gandavarapu, N.R., Mariner, P.D., Schwartz, M.P., and Anseth, K.S. Extracellular matrix protein adsorption to phosphate-functionalized gels from serum promotes osteogenic differentiation of human mesenchymal stem cells. Acta Biomater 9, 4525, 2013.

99. Aizawa, Y., and Shoichet, M.S. The role of endothelial cells in the retinal stem and progenitor cell niche within a 3D engineered hydrogel matrix. Biomaterials 33, 5198, 2012.

100. Aizawa, Y., Wylie, R., and Shoichet, M. Endothelial cell guidance in 3D patterned scaffolds. Adv Mater 22, 4831, 2011.

101. Silva, N.A., Cooke, M.J., Tam, R.Y., Sousa, N., Salgado, A.J., Reis, R.L., and Shoichet, M.S. The effects of peptide modified gellan gum and olfactory ensheathing glia cells on neural stem/progenitor cell fate. Biomaterials 33, 6345, 2012.

102. Choi, B.H., Choi, Y.S., Hwang, D.S., and Cha, H.J. Facile surface functionalization with glycosaminoglycans by direct coating with mussel adhesive protein. Tissue Eng Part C Methods 18, 71, 2012.

103. Hong, J.M., Kim, B.J., Shim, J.H., Kang, K.S., Kim, K.J., Rhie, J.W., Cha, H.J., and Cho, D.W. Enhancement of bone regeneration through facile surface functionalization of solid freeform fabrication-based three-dimensional scaffolds using mussel adhesive proteins. Acta Biomater 8, 2578, 2012.

104. Leipzig, N.D., Wylie, R.G., Kim, H., and Shoichet, M.S. Differentiation of neural stem cells in three-dimensional growth factor-immobilized chitosan hydrogel scaffolds. Biomaterials 32, 57, 2011.

105. Leipzig, N.D., Xu, C.C., Zahir, T., and Shoichet, M.S. Functional immobilization of interferon-gamma induces neuronal differentiation of neural stem cells. J Biomed Mater Res A 93A, 625, 2010.

106. Li, Y., Danmark, S., Edlund, U., Finne-Wistrand, A., He, X., Norgard, M., Blomen, E., Hultenby, K., Andersson, G., and Lindgren, U. Resveratrol-conjugated poly-epsilon-caprolactone facilitates in vitro mineralization and in vivo bone regeneration. Acta Biomater 7, 751, 2011.

107. Rodrigues, A.I., Gomes, M.E., Leonor, I.B., and Reis, R.L. Bioactive starch-based scaffolds and human adipose stem cells are a good combination for bone tissue engineering. Acta Biomater 8, 3765, 2012.

108. Santos, T.C., Marques, A.P., Horing, B., Martins, A.R., Tuzlakoglu, K., Castro, A.G., van Griensven, M., and Reis, R.L. In vivo short-term and long-term host reaction to starch-based scaffolds. Acta Biomater 6, 4314, 2010.

109. Tuzlakoglu, K., Pashkuleva, I., Rodrigues, M.T., Gomes, M.E., van Lenthe, G.H., Muller, R., and Reis, R.L. A new route to produce starch-based fiber mesh scaffolds by wet spinning and subsequent surface modification as a way to improve cell attachment and proliferation. $\underline{\text { J Biomed Mater }}$ Res A 92A, 369, 2010.

110. Santos, T.C., Morton, T.J., Moritz, M., Pfeifer, S., Reise, K., Marques, A.P., Castro, A.G., Reis, R.L., and van Griensven, M. Vascular endothelial growth factor and fibroblast growth factor-2 incorporation in starch-based bone tissueengineered constructs promote the in vivo expression of neovascularization mediators. Tissue Eng Part A 19, 834, 2013.

Address correspondence to: Filippo Rossi, PhD

Department of Chemistry Materials and Chemical Engineering "Giulio Natta" Politecnico di Milano

Via Mancinelli 7 Milan 20131 Italy

E-mail: filippo.rossi@polimi.it

Received: June 19, 2013

Accepted: September 10, 2013 Online Publication Date: November 8, 2013 